\title{
Caracterização morfogenética e reação de resistência de genótipos de tangerineira a Alternaria alternata f. sp. citri
}

\author{
Mirelly Miguel Porcino ${ }^{1}$, Luciana Cordeiro do Nascimento ${ }^{1}$, Jean de Oliveira Souza ${ }^{1}$, Breno Oliveira de Souza ${ }^{1}$, \\ Marciano Costa Nunes ${ }^{2}$
}

\begin{abstract}
${ }^{1}$ Programa de Pós-Graduação em Agronomia, Universidade Federal da Paraíba, CEP: 58397-000, Areia, PB.
${ }^{2}$ Departamento de Fitotecnia e Ciências Ambientais, Universidade Federal da Paraíba, CEP: 58397-000, Areia, PB.

Autor para correspondência: Mirelly Miguel Porcino (mirellyagroufpb@hotmail.com)

Data de chegada: 25/11/2016. Aceito para publicação em: 21/02/2017.
\end{abstract}

$10.1590 / 0100-5405 / 171161$

\section{RESUMO}

Porcino, M.M.; Nascimento, L.C.; Souza, J.O.; Souza, B.O.; Nunes, M.C. Caracterização morfogenética e reação de resistência de genótipos de tangerineira a Alternaria alternata f. sp. citri. Summa Phytopathologica, v.43, n.2, p.118-123, 2017.

Este trabalho teve como objetivo a caracterização morfogenética de dez isolados de Alternaria alternata f. sp. citri coletados no estado da Paraíba e avaliar a reação de cinco genótipos de tangerineira inoculados com $A$. alternata f. sp. citri. O experimento foi realizado na Universidade Federal da Paraíba. Dez isolados de $A$. alternata foram avaliados quanto à produção de conídios, índice de velocidade de crescimento micelial e crescimento micelial final. As inoculações de $A$. alternata foram em folhas destacadas e em mudas de tangerineiras de cinco genótipos, Tangelo Robinson', Tangerina 'Clementina', Tangerina 'Nova', Tangerina 'Lee' e Tangerina 'Swatow' e em frutos de tangerineira cv. "Dancy". Na inoculação das mudas foi utilizado o isolado 7, de Lagoa seca-PB que apresentou as melhores características morfológicas. As avaliações foram realizadas $48 \mathrm{~h}$ após a inoculação do patógeno, utilizando uma escala de notas. Os isolados 2 e 7 apresentaram maior velocidade de crescimento micelial e os isolados 6 e 7 causaram maior severidade da doença em frutos de cv. 'Dancy'. Sete grupos divergentes de A. alternaria f. sp. citri foram obtidos pelo marcador ISSR. Os genótipos 'Tangelo Robinson', Tangerina 'Swatow' e Tangerina 'Nova' apresentaram maior resistência a Mancha Marrom de Alternaria nas condições desse trabalho.

Palavras-chave: Mancha marrom de alternaria, severidade, agressividade, tangerina

\section{ABSTRACT}

Porcino, M.M.; Nascimento, L.C.; Souza, J.O.; Souza, B.O.; Nunes, M.C. Morphogenetic characterization and resistance reaction of mandarin orange genotypes to Alternaria alternata f. sp. citri. Summa Phytopathologica, v.43, n.2, p.118-123, 2017.

This study aimed to obtain morphogenetic characterization of ten isolates of Alternaria alternata f. sp. citri collected in the state of Paraíba and to evaluate the reaction of five mandarin orange genotypes inoculated with $A$. alternata f. sp. citri. The experiment was carried out at Federal University of Paraíba. Ten isolates of A. alternata were evaluated for conidial production, mycelial growth rate and final mycelial growth. A. alternata inoculations were done in detached leaves and seedlings of five mandarin orange genotypes, 'Tangelo Robinson', 'Clementina' Tangerine, 'Nova' Tangerine, 'Lee' Tangerine and 'Swatow' Tangerine, as well as in fruits of tangerine tree cv. 'Dancy'. In the inoculation of seedlings, isolate 7 was used, which was from Lagoa Seca-PB and presented the best morphological characteristics. Evaluations were performed at $48 \mathrm{~h}$ after the pathogen inoculation and used a scale of grades. Isolates 2 and 7 presented higher mycelial growth rate and isolates 6 and 7 caused greater disease severity in fruits of cv. 'Dancy'. Seven divergent groups of $A$. alternaria $\mathrm{f}$. sp. citri were obtained by the ISSR marker. Genotypes 'Tangelo Robinson', 'Swatow' Tangerine and 'Nova' Tangerine presented greater resistance to Alternaria brown spot under the conditions of the present study.

Keywords: Alternaria brown spot, severity, aggressiveness, tangerine

A Mancha Marrom de Alternaria (MMA) foi registrada pela primeira vez em Tangerina, cv. 'Emperor' (Citrus nobilis), na Austrália em 1903 Pegg (14) e denominou-se seu agente causal como Alternaria alternata (Fr.:Fr.) Keissl patótipo tangerina. No Brasil, relatou-se a MMA pela primeira vez em 2001 no Rio de Janeiro e seu primeiro relato na Paraíba (PB) foi em 2009. Essa doença se tornou um fator limitante na produção das tangerineiras, onde o Brasil reduziu, cerca de 14 mil hectares de área colhida de tangerina, que equivale a diminuição de, aproximadamente, 366 mil toneladas 2003 a 2013 (8). Isso faz referência ao constante abandono e deslocamento da citricultura vivenciado pelos produtores, na busca de novos segmentos produtivos.

Os sintomas da MMA ocorrem em folhas, ramos e frutos na forma de manchas de cor marrom ou preta, de tamanho variado, e com a evolução da doença causa necrose dos tecidos infectados (20). O tamanho das lesões e a expansão da necrose variam em função da suscetibilidade de genótipos de citros (17). Seus conídios são facilmente disseminados pelo vento e depositados na superfície das plantas, contribuindo para que essa doença seja um dos principais fatores limitantes à produção de tangerinas. As condições são favoráveis á infecção quando ocorre um período de molhamento de 10 a 12 horas e temperatura entre 20 e $30{ }^{\circ} \mathrm{C}(22)$. Dentre as principais medidas de manejo para a MMA, destacam-se o plantio de mudas sadias; realização de podas de limpeza; manutenção da nutrição e de sanidade das plantas, evitando o uso excessivo de irrigação (21).

Recomenda-se o emprego de genótipos resistentes aos patógenos, como método principal de controle de doenças em plantas. Este 
método representa um dos marcos significativos em termos de avanços tecnológicos na agricultura, por ser econômico, de fácil utilização, apresentar possibilidade de integração aos demais métodos de controle e por não causar danos ao meio ambiente (23). As tangerinas Fremont (Citrus clementina hort. ex Tanaka x Citrus reticulataBlanco) e tangerina Thomas são consideradas resistentes a MMA. Suas plantas são de porte reduzido (semi-anãs), os frutos apresentam características excepcionais para consumo in natura. No entanto a tangerina Fremont produz frutos de maturação tardia, ressaltando a importância da busca de novos genótipos de tangerineiras resistente a MMA e com características agronômicas desejáveis (17).

A primeira etapa de um programa de melhoramento genético de plantas para o desenvolvimento de materiais resistentes a uma determinada doença é avaliar a reação de genótipos aos patógenos (19). Além disso, para desenvolvimento das melhores estratégias de controle de doença em plantas é importante conhecer a variabilidade e estrutura populacional dos patógenos associados. Para isto é necessário o estudo da diversidade fenotípica e genotípica desses patógenos (17).

Diante do exposto, este trabalho teve como objetivo caracterizar fenotípica e genotipicamente dez isolados de Alternaria alternata e avaliar a reação de cinco genótipos de tangerineira a esses isolados em folhas destacadas e em mudas.

\section{MATERIAL E MÉTODOS}

Os experimentos foram conduzidos no Centro de Ciências Agrárias da Universidade Federal da Paraíba, UFPB em Areia, PB.

Para a realização desse trabalho foram obtidos isolados de $A$. alternata f. sp. citri de folhas e frutos sintomáticos de tangerineiras, oriundos de áreas de produção localizada em diferentes municípios do estado da Paraíba. Os isolados foram identificados de acordo com os municípios de origem, 1, 2 e 3 de Matinhas (Latitude: $6^{\circ} 53$ ' 30" Sul Longitude: $35^{\circ} 49^{\prime} 51$ ' Oeste); isolado 4 de Remígio (Latitude: $6^{\circ} 53^{\prime}$ 30" Sul Longitude: $35^{\circ} 49^{\prime}$ 51" Oeste); 5, 7, 8, 9 e 10 de Lagoa Seca (Latitude: $7^{\circ} 10^{\prime} 8^{\prime \prime}$ Sul Longitude: $35^{\circ} 51^{\prime} 20^{\prime}$ Oeste) e 6 de Alagoa Nova (Latitude: $7^{\circ} 4^{\prime} 5^{\prime}$ ' Sul Longitude: $35^{\circ} 45^{\prime} 40$ "' Oeste).

Pequenos fragmentos de tecido foliar e de frutos foram desinfestados, e plaqueados meio Batata Dextrose Ágar (BDA). As placas foram acondicionadas em estufa, tipo B.O.D. a $25 \pm 2{ }^{\circ} \mathrm{C}$ e fotoperíodo de doze horas. Após sete dias, nessas condições, os isolados foram repicados para o meio de carbonato de cálcio $\left(30 \mathrm{~g}\right.$ de $\mathrm{CaCO}_{3}$, $20 \mathrm{~g}$ de sacarose e $20 \mathrm{~g}$ de ágar $\mathrm{L}^{-1}$ ) a $25 \pm 2{ }^{\circ} \mathrm{C}$ e fotoperíodo de doze horas. Após sete dias, a confirmação da identidade morfológica dos isolados foi realizada observando-se as suas estruturas morfológicas em comparação a literatura especializada $(6,10)$.

\section{Diversidade morfofisiológica e genética dos isolados}

A caracterização morfológica dos isolados de A. alternata f. sp. citri foi avaliada em meio de carbonato de cálcio $\left(\mathrm{CaCO}_{3}\right)$ a $25{ }^{\circ} \mathrm{C}$ e fotoperíodo de doze horas (6). Os marcadores fenotípicos avaliados foram: índice de velocidade de crescimento micelial (IVCM), crescimento micelial final (CMF) e produção de conídios (PC). Além destes marcadores, foi avaliada a severidade dos isolados inoculados em frutas de tangerina cv. 'Dancy'.

O CMF foi avaliado pela quantificação do diâmetro $(\mathrm{cm})$ das colônias em dois sentidos diametralmente opostos, aos onze dias de idade dos isolados crescidos a $25^{\circ} \mathbf{C}$ e fotoperíodo de doze horas. Utilizando-se do crescimento micelial diário até o décimo primeiro dia de avaliação, obteve-se o índice de velocidade de crescimento micelial (IVCM), obtidos a partir da fórmula apresentada por Oliveira (12): $\mathrm{IVCM}=\Sigma(\mathrm{D}-\mathrm{Da}) / \mathrm{N}$, Onde: $\mathrm{IVCM}=$ índice de velocidade de crescimento micelial; $\mathrm{D}=$ diâmetro médio atual da colônia; $\mathrm{Da}=$ diâmetro médio da colônia do dia anterior; $\mathrm{N}=$ número de dias após a inoculação.

No último dia de avaliação, a PC $\left(10^{5}\right.$ esporos $\left./ \mathrm{mL}\right)$ foi obtida por meio da metodologia utilizada por Garcia (12), determinada ao final do crescimento micelial dos isolados, aos onze dias de idade.

A severidade (\%) ou área lesionada pelos isolados em tangerinas 'Dancy', em estágio de maturação C2 (7) foi quantificada a partir da utilização de uma escala de notas de severidade da MMA, proposta por Martelli (11), onde o diâmetro $\left(\mathrm{cm}^{2}\right)$ das lesões formadas nos frutos foi mensurado em dois sentidos diametralmente opostos pela utilização de um paquímetro digital.

Para isso, 1 disco de $5 \mathrm{~mm}$ de diâmetro da colonizados pelos isolados foram inoculados na região equatorial das frutas (com três furos de equidistantes de $0,9 \mathrm{~mm}$ superficiais), realizados com perfurador flambado, constando de 5 frutas para cada isolado. As frutas foram dispostas em bandejas de polietileno e cobertas com sacos plásticos borrifados com água destilada, para propiciar ambiente de câmara úmida por $48 \mathrm{~h}$. As avaliações de severidade foram realizadas a partir do quarto dia após as inoculações dos isolados, até o nono dia sob temperatura de $25 \pm 2{ }^{\circ} \mathrm{C}$ e fotoperíodo de doze horas (11).

Culturas monospóricas dos isolados foram obtidas por meio da coleta de um conídio ao microscópio de luz. O conídio foi coletado pelo corte de um fragmento circular, correspondente ao foco de luz do microscópio. Os isolados foram transferidos para tubos de ensaio com BDA por sete dias a temperatura de $25 \pm 2{ }^{\circ} \mathrm{C}$ e fotoperíodo de doze horas, até o momento do uso.

Os monospóricos obtidos foram multiplicados em placas de Petri contendo meio BDA acrescido de 0,12 g de antibiótico (Amoxicilina, $500 \mathrm{mg}$ ) e, após sete dias, dois discos foram transferidos para tubos de ensaio com $30 \mathrm{~mL}$ de meio BD (Batata $200 \mathrm{~g}$-Dextrose $20 \mathrm{~g}$ ). Durante sete dias os tubos foram agitados duas vezes ao dia por 30 minutos por agitador mecânico (modelo AX685/2). Posteriormente toda a massa micelial foi retirada dos tubos de ensaio para ser macerada com nitrogênio líquido.

A extração do DNA foi realizada em microcentrífuga utilizando o kit UltraClean ${ }^{\circledR}$ Microbial DNA, com protocolo descrito pelo fabricante MO BIO laboratories Inc Carlsbad, CA., EUA. O DNA total corado com GelRed Biotium ${ }^{\circledR}$ foi analisado em gel de agarose a $1 \%$, visualizado em luz ultravioleta (UV) e quantificado em espectofotômetro NanoDrop 2000 da Thermo Scientific. A concentração de DNA total extraída variou de 8 a $20 \mathrm{ng} / \mu \mathrm{L}$ e foi ajustada a $10 \mathrm{ng} / \mu \mathrm{L}$ para reações.

As reações ISSR foram realizadas utilizando o kit Platinum ${ }^{\mathbb{R}}$ PCR SuperMix da Invitrogen ${ }^{\text {TM }}$ em termociclador Techne (TC-5000, Inc, Inglaterra). Nas reações, cinco primers ISRR foram utilizados, a saber: CA3 (AGCACA CAC ACA CAC ACA), CAC5 (GTC CAC CACCACCAC CAC), CA1 (ACC ACA CAC ACA CAC ACA), CA2 (ATC ACA CAC ACA CAC ACA) e CAC3 (ATG CAC CACCACCAC CAC). Utilizou-se desnaturação inicial de $94{ }^{\circ} \mathrm{C}$, por 4 min em 40 ciclos: $94^{\circ} \mathrm{C}$, por $40 \mathrm{~s}$; anelamento, que variou $45^{\circ} \mathrm{C}$ a $47^{\circ} \mathrm{C}$, de acordo com o primer ISSR utilizado; extensão a $72^{\circ} \mathrm{C}$, por 2 min; extensão final a $72{ }^{\circ} \mathrm{C}$ por 7 minutos. Os produtos das reações ISRR foram submetidos a eletroforese em gel de agarose a $1 \%$ e corados com GelRed Biotium $^{\circledR}$. Os marcadores ISRR foram visualizados e registrados em fotodocumentador digital UVP Life Science Software.

Foi realizada análise entre os produtos ISSR dos isolados por meio da obtenção das médias aritméticas dos grupos em pares de dados combinados (UPGMA). O coeficiente de similaridade de Jaccard, a 
$2 \%$ de tolerância foi utilizado para determinar a similaridade genética entre os grupos formados e observados em um dendrograma gerado pelo software BioNumerics ${ }^{\circledR}$.

\section{Reação de genótipos de tangerineiras}

A avaliação da patogenicidade a $A$. alternata f. sp. citri foi avaliada em folhas destacadas, onde foram preparadas cinco placas de Petri para cada isolado, correspondendo a cinco repetições por genótipo de tangerineira, sendo por cvs. Tangelo Robinson, Tangerina Clementina, Tangerina Nova, Tangerina Lee e Tangerina Swatow.

As folhas para as inoculações dos isolados de A. alternata f. sp. citri foram retiradas de ramos jovens, que, foram acondicionados em caixas de isopor e transportadas do campo até o Laboratório. As folhas apresentavam-se íntegras e uniformes quanto à sua maturidade. Cada folha teve o pecíolo envolto por um chumaço de algodão umedecido com água esterilizada, em seguida o limbo foliar foi pulverizado com suspensões de $10^{5}$ conídios $\mathrm{mL}^{-1}$ dos isolados até o ponto de escorrimento e dispostas em placas de Petri contendo dupla camada de papel filtro umedecido. Essas placas foram mantidas à temperatura ambiente de $25 \pm 2^{\circ} \mathrm{C}$ em câmara tipo B.O.D. As avaliações iniciaram 48 horas após a inoculação e foram realizadas por 20 dias consecutivos. A escala de notas de severidade foi a mesma utilizada para frutas (11).

Os isolados também foram inoculados em mudas de tangerineiras enxertadas. Tendo como porta-enxerto limão-cravo (Citrus limonium). Os enxertos ou borbulhas dos genótipos de tangerineira foram obtidos do banco de Germoplasma do Setor de Fruticultura da UFPB. Eles foram circundados com fita biodegradável de polietileno até o início da brotação foliar. Posteriormente, realizou-se uma poda para induzir brotações e a formação de mais folhas jovens.

Para a reação dos genótipos de tangerineira em mudas foram utilizadas as cultivares de Tangelo Robinson e Tangerina Clementina, Nova, Lee e Swatow por serem comumente cultivadas na Paraíba (16).

A inoculação das mudas foi realizada 120 dias após a enxertia, quando as mudas apresentavam de 6 a 8 folhas definitivas. Utilizouse uma suspensão conidial na concentração 105 conídios mL-1 do isolado 7. Antes da inoculação, foi realizado um corte superficial na parte abaxial das folhas, seguido de aspersão do inóculo até o ponto de escorrimento. As mudas foram cobertas com saco plástico transparente durante $36 \mathrm{~h}$ para propiciar uma câmara úmida. As avaliações da severidade da doença foram realizadas a partir do terceiro dia após a inoculação até o vigésimo primeiro dia e utilizou-se a escala diagramática descrita por Martelli (11).

$\mathrm{O}$ delineamento experimental utilizado foi o inteiramente casualizado (DIC). A diversidade morfofisiológica dos isolados foi avaliada em cinco placas de Petri, onde cada placa de Petri foi considerada como uma repetição. A agressividade dos isolados foi avaliada utilizando-se cinco frutos de tangerina 'Dancy' por isolado e cada fruto inoculado foi considerado como uma repetição. Quatro mudas foram utilizadas para avaliação da reação dos genótipos ao patógeno sendo cada muda considerada como uma repetição.

Os dados de cada ensaio foram transformados em raiz de $\mathrm{x}+1$ e submetidos à análise de variância (ANOVA) pelo programa estatístico $\mathrm{SAS}^{\circledR}$. Quando o teste $\mathrm{F}$ das análises de variância foi significativo, as médias foram comparadas pelo teste de Scott-Knott até 5\% de probabilidade pelo programa SISVAR ${ }^{\circledR}$.

\section{RESULTADOS E DISCUSSÃO}

Elevada e significativa diversidade fenotípica foi observada nos isolados de A. alternata, patótipo tangerina analisados. $\mathrm{O}$ crescimento micelial final (CMF), índice de velocidade de crescimento micelial (IVCM) e a agressividade dos isolados foram diferencialmente significativos. A produção de conídios foi igual para os isolados analisados. Notou-se que os isolados 2 (Matinhas) e 7 (Lagoa Seca) foram os que cresceram em maior diâmetro e velocidade nas condições de cultivo in vitro avaliadas, com 1,20, 1,17 de IVCM e 2,35, 2,30 $\mathrm{cm}^{2}$ de CMF, respectivamente (Tabela 1 ).

Os isolados 3, 4, 9 e 10 expressaram os menores valores de IVCM, com 1,14. Esse resultado do IVCM entre os isolados de Alternaria alternata $\mathrm{f}$. sp. citri pode ser atribuído a diversidade no crescimento micelial entre os isolados de uma mesma origem geográfica, sugerindo que a variabilidade para o caráter avaliado poderá ser elevada entre as populações de isolados coletados, tanto em locais iguais como em locais diferentes (14). Dessa forma, a velocidade de crescimento micelial dos isolados avaliados no presente estudo pode ser estabelecida a características genéticas intrínsecas ao patógeno e as condições do ambiente de avaliação (3).

Os frutos de tangerineira cv. "Dancy" inoculados com A. alternata f. sp. citri apresentaram maior suscetibilidade durante o período de

Tabela 1. Diversidade fenotípica entre isolados de Alternaria alternata, patótipo tangerina coletados no estado Paraíba.

\begin{tabular}{|c|c|c|c|c|c|}
\hline Isolados & Procedência & $\mathbf{P C}^{1}$ & IVCM $^{2}$ & $\mathrm{CMF}^{3}$ & Severidade \\
\hline 1 & Matinhas & $1,04 a^{*}$ & $1,14 \mathrm{c}$ & $1,99 b$ & $1,44 d$ \\
\hline 2 & Matinhas & $1,06 \mathrm{a}$ & $1,20 \mathrm{a}$ & $2,35 \mathrm{a}$ & $2,34 b$ \\
\hline 4 & Remígio & $1,05 \mathrm{a}$ & $1,14 \mathrm{c}$ & $1,98 b$ & $2,15 b$ \\
\hline 5 & Lagoa Seca & $1,09 \mathrm{a}$ & $1,16 \mathrm{~b}$ & $2,10 \mathrm{~b}$ & $2,06 \mathrm{~b}$ \\
\hline 8 & Lagoa Seca & $1,08 \mathrm{a}$ & $1,16 \mathrm{~b}$ & $2,39 \mathrm{a}$ & $2,35 b$ \\
\hline 9 & Lagoa Seca & $1,08 \mathrm{a}$ & $1,14 \mathrm{c}$ & $1,98 b$ & $1,87 \mathrm{c}$ \\
\hline \multirow[t]{2}{*}{10} & Lagoa Seca & $1,05 \mathrm{a}$ & $1,14 \mathrm{c}$ & $1,99 b$ & $2,07 \mathrm{~b}$ \\
\hline & $\mathrm{CV}(\%)$ & 7,88 & 2,36 & 17,18 & 11,95 \\
\hline
\end{tabular}

${ }^{1}$ Produção de Conídios; ${ }^{2}$ Índice de Velocidade de Crescimento Micelial; ${ }^{3}$ Crescimento Micelial Final. *Médias seguidas da mesma letra não diferem pelo teste de Scott-Knott a 5\% de probabilidade *Médias seguidas pela mesma letra não diferem entre si pelo teste de Scott-knott ao nível de até 5\% de probabilidade. Os dados foram transformados em $\sqrt{ } \mathrm{X}+1$. 
avaliação, com destaque para os isolados 6 (Alagoa Nova) e 7 (Lagoa Seca) que apresentaram maior severidade da doença. (Tabela 1). Segundo a literatura, também foi verificado alta suscetibilidade em tangerina 'Dancy', em mandarina 'Fortune' e em Tangor 'Murcott' à formação de folhas jovens (21).

Dos cinco "primers" ISSR utilizados nas reações PCR, quatro foram eficientes em detectar a diversidade genética nos isolados. A partir das amplificações, obtiveram-se com base no coeficiente de similaridade, sete grupos genéticos diferentes. O primeiro grupo, formado pelos isolados 1 e 7; o segundo pelos isolados, 6, 8, 10 e os grupos restantes foram formados pelos demais isolados, individualmente. A similaridade genética pelo coeficiente de Jaccard variou de 33 a 100\% entre os grupos de isolados apresentados (Figura 1).

Foi detectada elevada diversidade genética entre os isolados avaliados por meio dos marcadores ISSR. Semelhantemente, DiniAndreote et al. (4) identificaram elevada variabilidade entre 24 isolados de A. alternata f. sp. citri por meio dos marcadores RAPD e RFLP. Assim como no presente trabalho, foi verificado que mesmo utilizando uma população pequena de isolados do patógeno nas avaliações, a diversidade apresentou-se elevada.

Por meio do marcador ISSR foi possível constatar alta diversidade entre os isolado 1 de Matinhas e o isolado 4 de Remígio. Por outro lado, os isolados, 10 de Lagoa Seca e o 6 de Alagoa Nova apresentaram baixa distância genética entre os locais amostrados. Não foi observada relação entre os grupos de similaridade genética formados e a origem geográfica dos isolados. Isso demonstra que tanto os isolados provenientes de uma mesma região, como de regiões diferentes são divergentes (Figura 1).

Formas de reprodução como a heterocariose e a parassexualidade são fatores cruciais na determinação da heterogeneidade fenotípica dentro de um grupo de isolados fúngicos ou entre espécies (9). Essas formas de recombinação genética entre os microrganismos podem ocorrer em regiões onde a produção agrícola ocorre de forma intensiva e com elevada utilização de agrotóxicos, como são caracterizadas as regiões de Citrus amostradas no presente estudo.

É possível que a elevada variabilidade observada entre os isolados deste estudo seja decorrente de eventuais recombinações genéticas, que ocorreram nas regiões de cultivo amostradas. Essas recombinações podem acontecer devido a permanência de estruturas reprodutivas dos patógenos nos locais de cultivos entre uma safra e outra (6).

Testes de resistência e suscetibilidade as patotoxinas ACT e ACR de $A$. alternata em citros foram realizados por vários pesquisadores, incluindo Stuart et al. (19) e Stewart et al. (14). No presente trabalho, quando realizada a inoculação em folhas destacadas, os genótipos estudados mostraram-se suscetíveis, com pouca variação na severidade da doença (1,3 a 1,7\%).

Infecções em folhas de citros por A. alternata f. sp. citri ocorrem, normalmente, no estágio foliar inicial, devido a parede celular não está totalmente formada, facilitando a penetração do patógeno, dessa forma, nesse estágio, as folhas apresentam maior severidade da doença. Essa comprovação já foi observada por Reis (17), quando afirmou que o maior número de lesões ocorre em folhas, diminuindo estas à medida que as folhas amadurecem. Dessa forma, os mecanismos de ataque do patógeno e de defesa do hospedeiro são importantes para melhor compreensão dos resultados analisados no presente estudo. Conforme a literatura mostra, os genótipos de tangerina resistentes não dependem apenas de mecanismos físicos para impedir o desenvolvimento da doença e que o mecanismo de resposta deve estar ligado a processos bioquímicos no momento em que o patógeno tenta colonizar o tecido (7, 20).

Espécies cítricas suscetíveis a A. alternata pv. citri foram avaliados por Vicent et al. (21), em folhas destacadas, em condição de laboratório. Estes pesquisadores relataram que os sintomas podem ter sido influenciados pelas condições experimentais, ou seja, pode estar relacionado à alternância de luminosidade, temperatura e condições de umidade, que são inteiramente controladas nos ensaios 'in vitro'. Estes fatores podem ter contribuído para a variação nos níveis de resistência e suscetibilidade a A. alternata f. sp. citri observados no presente estudo.

Espécies cítricas suscetíveis a A. alternata pv. avaliadas por Vicent et al. (21), em folhas destacadas, comenta que esses sintomas podem ser influenciados pelas condições experimentais, ou seja, podem estar relacionada à alternância de luminosidade, temperatura e condições de umidade, que são inteiramente controladas nos ensaios 'in vitro'. Estes fatores podem ter contribuído para a variação nos níveis de resistência e suscetibilidade a A. alternata $\mathrm{f}$. sp. citri observados no presente estudo (3).

Todos os genótipos avaliados em severidade apresentaram lesões ocasionadas por A. alternata f. sp. citri. Foi observada diferenças

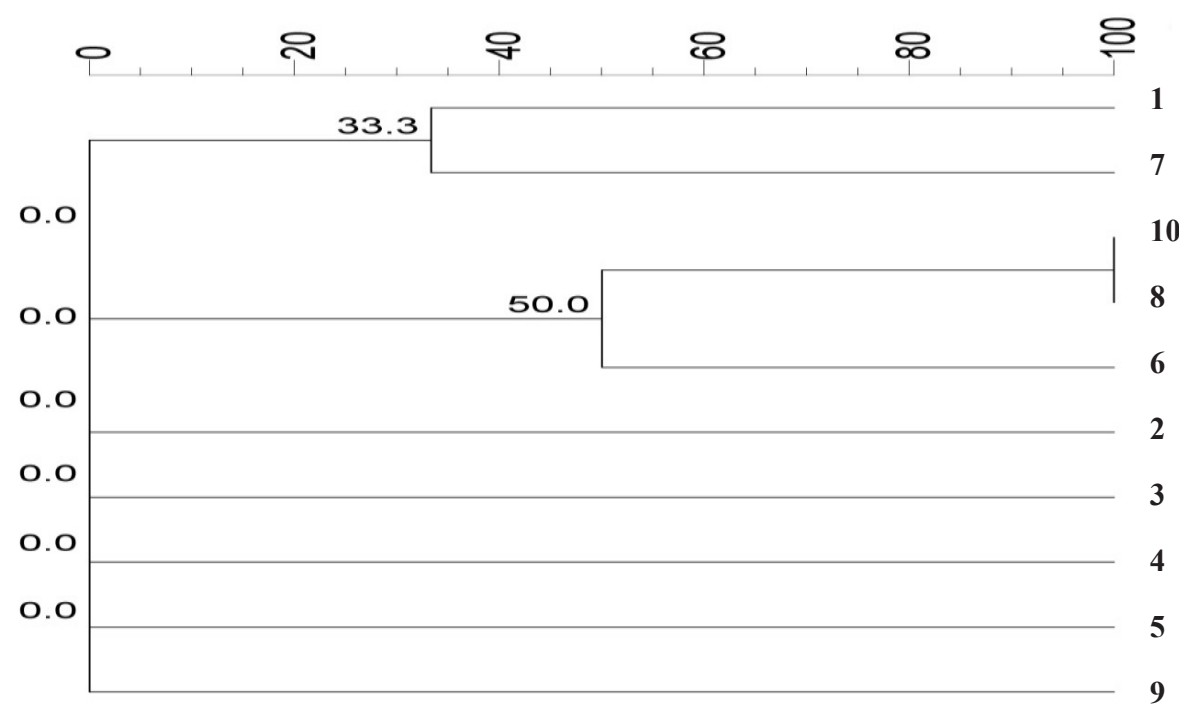

Figura 1. Diversidade genética entre isolados de A. alternata, patótipo tangerina. Areia, PB, 2016. 1, 2 e 3, isolados de Matinhas, PB; 5, 7, 9 e 10, isolados de Lagoa Seca, PB e 4, isolado de Remígio, PB. *Similaridade genética de Jaccard. 
significativas entre a severidade destes genótipos, onde a tangerineira 'Lee' $(4,5 \%)$ e a tangerineira 'Clementina' $(4,4 \%)$ apresentaram os maiores níveis de severidade. No entanto, os genótipos 'Tangelo Nova' (1,5\%), 'Tangelo Robinson' (3,0\%) e tangerineira 'Swatow' $(2,0 \%)$ evidenciaram as menores taxas de severidade da mancha-marrom de Alternaria (Tabela 2).

Tabela 2. Reação de genótipos de tangerineiras inoculadas com Alternaria alternata f. sp. citri.

\begin{tabular}{lc}
\hline \multicolumn{1}{c}{ Genótipos } & Severidade \\
\hline Tangelo Robinson & $3,0 \mathrm{~b}$ \\
Tangerina Nova & $1,5 \mathrm{~b}$ \\
Tangerina Lee & $4,5 \mathrm{a}$ \\
Tangerina Swatow & $2,0 \mathrm{~b}$ \\
Tangerina Clementina & $4,4 \mathrm{a}$ \\
\hline $\mathrm{CV}(\%)$ & 49,27 \\
\hline
\end{tabular}

*Médias seguidas da mesma letra não diferem pelo teste de Scott-knott até 5\% de probabilidade.

Ainda existem poucos estudos sobre o não estabelecimento de $A$. alternata em tecidos de variedades resistentes. Essa resistência pode está relacionado a vias de produção de etileno e ácido jasmônico, que segundo Stuart (19) seus resultados mostram que existe diferença entre a regulação dessas vias quando se compara variedades resistentes e variedades suscetíveis. As folhas dos genótipos avaliadas, no presente trabalho envelheceram rapidamente e isso pode ter contribuído a baixa severidade de doença quantificada.

As mudas de tangerineira 'Nova' apresentaram a menor severidade da mancha-marrom de Alternaria. Similarmente, Reis (17) trabalhando a cultivar 'Nova' demonstrou que esse genótipo é mais resistente, pela observação do menor tamanho de lesão em todos os estádios de maturação das frutas avaliados.

Mediante inoculações em diferentes cultivares de tangerina, com vários isolados Stewart et al. (14), demonstraram que a cultivar 'Nova' sempre revelou-se ser mais resistente do que 'Minneola', 'Orlando' e 'Sunburst', corroborando com os resultados obtidos para o genótipo 'Nova' no presente trabalho.

Similarmente, reações de suscetibilidade a Alternaria spp. têm sido relatadas em vários patossistemas em A. alternata em batata (5), A. alternata em açafrão (12) e A. helianthi em girassol (1).

Este trabalho observou uma elevada diversidade intra e entre isolados de diferentes populações de A. alternata que causam a mancha-marrom em diferentes genótipos de tangerineiras. Dessa forma, outros estudos com uma população maior de isolados de diferentes procedências devem ser realizados. Portanto, pode-se afirmar que os genótipos tangelo 'Robinson', Tangerina 'Swatow' e Tangerina 'Nova' são resistentes à Alternaria alternata podendo ser utilizados como fontes de resistências a $A$. alternata $\mathrm{f}$. sp. citri em futuros programas de melhoramento genético de tangerineiras, visando o controle da mancha-marrom de Alternaria.

\section{AGRADECIMENTOS}

A Universidade Federal da Paraíba, Laboratório de Fitopatologia e ao Laboratório de Produtos de Origem Animal.

\section{REFERÊNCIAS}

1. Allen, S.J.; Brown, J.F.; Kochman, J. K. Effect of leaf age, host growth stage, leaf injury, and pollen on the infection of sunflower Alternaria helianthi. Phytopathology, St. Paul, v.73, n. 6, p. 896-898, 1983.

2. Chagas, E.A.; Cazetta, J.O.; Lemos, E. G. M.; Pasqual, M.; Gomes, A.; Ramos, J.D.; Pio, R.; Barbosa, W.; Mendonça, V.; Ambrosio, L.A. Identificação de híbridos de citros resistentes à mancha-marrom-de-alternaria por meio de FAFLP e testes de patogenicidade. Pesquisa Agropecuária Brasileira, Brasília, v.42, p. 975-983, 2009.

3. Colturato, A.B. Efeito do meio de cultura, temperatura, fotoperíodo e fungicidas no crescimento micelial e no controle de Alternaria alternata f. sp. citri, causador da mancha marrom do tangor murcote. Dissertação (Proteção de Plantas) - Faculdade de Ciências Agronômicas, Universidade Estadual Paulista, Botucatu. 2006.

4. Dini, A. P. Pathogenicity of Alternaria alternata on markers RAPD e RFLP. Phytopathology, St. Paul, v. 7, n. 3, p. 201-212, 2009.

5. Droby, S.; Dinoor, A.; Prusky, D.; Barkai-golan, R. Pathogenicity of $\mathrm{Al}$ ternaria alternata on potato in Israel. Phytopathology, St. Paul, v. 74, n. 5, p. 537-542, 1984.

6. Hyun, J. W.; YI, S. H. ; Mackenzie, S. J. ; Timmer, L. W. ; Kim, K. S.; Lim, H. C. Pathotypes and genetic relationship of worldwide collections of Elsinoë spp. causing scab diseases of citrus. Phytopathology, Alemanha, v. 99 , p. $721-728,2010$

7. Iakimova, E. T.; Michalczuk, L.; Woltering, E. J. Hypersensitive cell death in plants: its mechanisms and role in plant defence against pathogens. Journal of Fruit and Ornamental Plant Research, Polonia, v. 13, p.134-158, 2006.

8. IBGE - Instituto brasileiro de geografia e estatística: Produção agrícola mundial. Disponível em: . Acesso em: 12 jan. 2016.

9. Jeffries, P.; Dodd, J. C.; Jeger, M. J.; Plumbley, R. A. The biology and control of Colletotrichum species on tropical fruit crops. Plant Pathology, Edinburg, v.39, n.3, p.343-366, 1990.

10. Kaufmann, P. J.; Weidemann, G. J. Isozyme analysis of Colletotrichum gloeosporioides from five host genera. Plant Disease, St. Paul, v.80, n.11, p.1289-1293, 1996.

11. MARTELLI, I. B. et al. Positive relationship between citrus leaf miner and alternaria brown spot. Ciência Rural, Campinas, SP. v.45, n.7, p.3, 2015.

12. Mortensen, K.; Bergman, J. W.; Burns, E. E. Importance of Alternaria carthami and A. alternata in causing leaf diseases of safflower. Plant Disease, St. Paul, v.67, n.11, p.1187-1190, 1983.

13. Oliveira, J. A. Efeito do tratamento fungicida em sementes no controle de tombamento de plântulas de pepino (Cucumis sativus L.) e pimentão (Capsicum annum L.). Dissertação (Mestrado em Fitossanidade) - Universidade Federal de Lavras, Lavras. 2010.

14. Stewart, J. E.; Thomas, K. A.; Lawrence, C. B.; Dang, H.; Pryor B. M.; Timmer, L. M.; Peever, T. L. Signatures of recombination in clonal lini eages of the citrus brown spot pathogen, Alternaria alternata sensu lato. Phytopathology, Washington, v.3, p.103, 2013.

15. Pegg, K.G. Studies of a strain of Alternaria citri Pierce, the causal agent of brown spot of Emperor mandarin. Queensland Journal of Agricultural and Animal Sciences, Brisbane, v.23, n.1, p.15-28, 1966.

16. Rappa, C. Busca da qualidade é destaque no VII Dia da Tangerina. Informativo Centro de Citricultura, Cordeirópolis, n. 108, p.2295-2297, 2004.

17. Reis, R. F.; Rinaldo, D.; Cottas, M. P.; Goes, A. Effectiveness of fungicide pyraclostrobin applied at different intervals, alone or in combination with mancozeb or copper axychloride, in Alternaria alternata control, the causal agent of Alternaria brown spot. Fitopatologia Brasileira, Brasília, v.31, p.273, 2007.

18. Souza, M. C. Reação de genótipos de tangerinas a Alternaria alternata e Elsinoe fawcettii: resistência, suscetibilidade e acúmulo de metabólitos. Jaboticabal, 2010.

19. Stuart, R. M.; Kubo, K. S.; Boava, L. P.; Bastianel, M.; Machado, M. A. Jasmonic acid and Ethylene signaling pathways are involved in citrus defenses against A. alternate "tangerine pathotype". In: OzBio2010, Campinas, SP, p. 145. 2010.

20. Stuart, R. M. Análise da interação entre citros e Alternaria alternata patótipo tangerina. p.28-32. Tese (Doutorado em Genética e Biologia Molecular) - Instituto de Biologia, Universidade Estadual de Campinas, Campinas. 2011.

21. Töfoli, J. G. et al. Potato late blight and early blight: importancy, charace teristics and sustainable management. Biológico, São Paulo, v.75, n.1, 
p.33-40, 2013.

22. TIMMER, L. W.; SOLEIL, Z. \& OROZCO-SANTOS, M. Alternaria Brown Spot of mandarines. In: TIMMER, L. H.; GARNSEY, S. M. \& GRAHAM, J. H. (Eds). Compendium of Citrus Diseases. Minnesota: APS Press ST Paul. v. 1, n.2, p.19-20. 2000

23. Vicent, A.; Badal, J.; Asensi, M. J.; Sanz, N.; Armengol, J.; García-Jiménez, J. Laboratory evaluation of citrus cultivars susceptibility and influence of fruit size on 70 Fortune mandarin to infection by Alternaria alternata pv. citri. European Journal of Plant Pathology, Dordrecht, v.110, n.3, p.245-251, 2012.

24. PADUA, J. M. V. Implicações da seleção precoce para resistência à antracnose no melhoramento genético do feijoeiro. $74 \mathrm{p}$. Dissertação (Mestrado em Genética e Melhoramento de Plantas) - Universidade Federal de Lavras, Lavras, 2013 